\title{
The effect of aluminium and phosphorus on the stability of individual austenite grains in TRIP steels
}

\author{
E. Jimenez-Melero ${ }^{\text {a,b,* }}$, N.H. van Dijk ${ }^{\text {a }}$, L. Zhao ${ }^{\text {b,c }}$, J. Sietsma ${ }^{c}$, S.E. Offerman ${ }^{c}$, \\ J.P. Wright ${ }^{\mathrm{d}}$, S. van der Zwaag ${ }^{\mathrm{e}}$ \\ ${ }^{a}$ Fundamental Aspects of Materials and Energy, Faculty of Applied Sciences, Delft University of Technology, Mekelweg 15, \\ 2629 JB Delft, The Netherlands \\ ${ }^{\mathrm{b}}$ Materials Innovation Institute M2i, Mekelweg 2, 2628 CD Delft, The Netherlands \\ ${ }^{c}$ Department of Materials Science and Engineering, Delft University of Technology, Mekelweg 2, 2628 CD Delft, The Netherlands \\ ${ }^{\mathrm{d}}$ European Synchrotron Radiation Facility, 6 Rue Jules Horowitz, BP 220, 38043 Grenoble Cedex, France \\ ${ }^{\mathrm{e}}$ Faculty of Aerospace Engineering, Delft University of Technology, Kluijverweg 1, 2629 HS Delft, The Netherlands
}

Received 9 July 2008; accepted 25 September 2008

Available online 25 October 2008

\begin{abstract}
We have performed in situ synchrotron X-ray diffraction experiments to assess the influence of aluminium and phosphorus on the austenite stability in low-alloyed transformation-induced plasticity steels during the high-temperature bainitic holding and the subsequent martensitic transformation during cooling to temperatures between room temperature and $100 \mathrm{~K}$. Although the addition of aluminium increases the chemical driving force for the formation of bainitic ferrite plates significantly, the phosphorus exerts a larger influence on the bainitic transformation kinetics. Consequently, the addition of phosphorus leads to a higher degree of carbon enrichment and a narrower grain volume distribution of the metastable austenite. The stability of the individual austenite grains with respect to their martensitic transformation depends on both the local carbon content and the grain volume for austenite grains smaller than $20 \mu \mathrm{m}^{3}$. The presence of aluminium and phosphorus further stabilizes the austenite grains.
\end{abstract}

(C) 2008 Acta Materialia Inc. Published by Elsevier Ltd. All rights reserved.

Keywords: TRIP steels; Polyphase microstructure; Metastable phases; Martensitic phase transformation; Synchrotron radiation

\section{Introduction}

Low-alloyed transformation-induced plasticity (TRIP) steels are attracting an increasing attention within the automotive industry, because their outstanding combination of strength and formability permits the formation of thin metal sheets into complex geometries for car body components $[1,2]$. They contain a relatively small amount of metastable austenite (less than $20 \mathrm{vol} . \%$ ) in a complex ferrite/ bainite/martensite microstructure $[3,4]$. The austenite phase

\footnotetext{
${ }^{*}$ Corresponding author. Address: Fundamental Aspects of Materials and Energy, Faculty of Applied Sciences, Delft University of Technology, Mekelweg 15, 2629 JB Delft, The Netherlands. Tel.: +31 15 2781192; fax: +31 152788303 .

E-mail address: E.Jimenez-Melero@tudelft.nl (E. Jimenez-Melero).
}

is retained at room temperature in a metastable state by the combined effect of alloying elements and a two-step thermal processing route. The latter consists of an intercritical annealing in the austenite $(\gamma)$-ferrite $(\alpha)$ stability region, followed by a quenching to a lower temperature at which part of the intercritical austenite transforms into bainite. The delay of the cementite $\left(\mathrm{Fe}_{3} \mathrm{C}\right)$ precipitation during the bainitic transformation leads to carbon enrichment of the remaining austenite phase, so that it withstands the subsequent quench to room temperature and remains in a metastable state in the final TRIP microstructure [5].

One crucial step to controlling the amount and stability of retained austenite at room temperature is the selection of the alloying elements that influence the phase transformations taking place during the processing of the TRIP steel. A significant number of both $\gamma$-stabilizing elements (car- 
bon, manganese, copper, nickel) and elements (silicon, aluminium, phosphorus) delaying the formation of $\mathrm{Fe}_{3} \mathrm{C}$ have been used in recent years to optimize the retained austenite characteristics for improved combinations of strength and formability [6-13]. An additional strength increase can be achieved when vanadium, titanium, molybdenum or niobium is added to the starting material. This is due to a precipitation hardening effect, coupled with a grain refinement of the ferritic matrix [14-17]. The effect of the chemical composition on the intercritical annealing and bainitic transformation steps is commonly studied in situ by dilatometry experiments in combination with optical microscopy. However, the majority of experimental efforts have focused on the unequivocal identification of the different phases present in the final TRIP steel microstructure, and on determining the average characteristics of the retained austenite (phase fraction and average carbon content). The austenite stability with respect to the martensitic transformation is subsequently assessed by following its phase fraction as a function of applied stress and/or temperature $[3,9,18,19]$.

However, this experimental evidence of an average character has proved to be insufficient to properly control the stability of the austenite phase to achieve an optimal combination of formability and strength for a selected application by varying the overall chemical composition of the starting material $[20,21]$. Besides that, the improvement of the formability and/or strength by the addition of certain beneficial alloying elements is normally accompanied by the deterioration of other relevant material properties, such as weldability or galvanizability $[10,11,22,23]$. It is also worth mentioning that the ongoing development of multiscale TRIP models $[24,25]$ requires accurate experimental information at the level of individual austenite grains, in order to give realistic predictions of the macroscropic mechanical response of TRIP steels.

We have recently demonstrated that it is possible to study the stability of individual metastable austenite grains within the bulk TRIP microstructure by performing in situ high-energy synchrotron X-ray diffraction experiments $[26,27]$. Our results revealed a broad distribution in carbon content and grain volume within the room-temperature austenite phase, which results in large variations in stability from grain to grain. The experimentally observed influence of the grain volume on the austenite stability has recently been recognized in the multiscale modelling of TRIP steels [28]. The present paper aims to determine the influence of aluminium and phosphorus on both the high-temperature processing of the TRIP steel and on the martensitic transformation of the austenite grains retained at room temperature in the resultant microstructure. These alloying elements are frequently regarded as an alternative to reduce the amount of silicon in low-alloyed TRIP steels, in order to overcome the hot-dip galvanizing problems due to the surface formation of $\mathrm{SiO}_{2}$ and $\mathrm{Mn}_{2} \mathrm{SiO}_{4}[10,11,13]$. For this purpose, we carried out a detailed characterization of the room-temperature austenite phase present in TRIP steels that differ in the aluminum and phosphorus content. We then assessed the stability of the individual retained austenite grains by monitoring their thermally induced martensitic transformation in situ during stepwise cooling of the material from room temperature to $100 \mathrm{~K}$. The results of the present study will provide guidelines for the control of the stability of the metastable austenite grains for optimal mechanical properties via a well-based choice of the initial chemical composition of the TRIP material. Furthermore, they will also contribute to narrow the gap that currently exists between the experimental studies on TRIP steels (mainly on an average scale) and the development of multiscale models, the foundations of which lie in an inadequate description of the martensitic transformation of the individual austenite grains embedded in the complex multiphase TRIP microstructure.

\section{Experimental}

Three TRIP steels with different concentrations of aluminium and phosphorus were used in this study $\left(\mathrm{Al}_{0.4}\right.$, $\mathrm{Al}_{1.8}$ and $\left.\mathrm{Al}_{0.4} \mathrm{P}_{0.1}\right)$. The chemical composition of the starting materials is presented in Table 1. An initial chemical characterization with energy-dispersive X-ray spectroscopy (EDS) excluded the occurrence of $\mathrm{Al}, \mathrm{Mn}$ or Si segregation in the three hot-rolled starting materials. Cylindrical samples with a diameter of $0.50 \mathrm{~mm}$ and a length of $2.0 \mathrm{~mm}$ were machined from the hot-rolled sheet material. The cylindrical axis of the samples was selected to be parallel to the rolling direction of the sheet material. The samples were heated in a salt bath to a temperature in the $\gamma / \alpha$ stability region. Since the boundaries of this two-phase region vary significantly with the chemical composition of the material, the thermodynamic transformation temperatures $A_{1}^{-}, A_{1}^{+}$and $A_{3}$ were calculated with the thermodynamic database MTDATA for the three studied compositions. The intercritical annealing temperature $\left(T_{\mathrm{i}}\right)$ was then chosen for each of the three TRIP steels, in order to obtain the maximum fraction of metastable austenite retained in their room-temperature microstructure. The holding time at the intercritical annealing temperature $\left(t_{\mathrm{i}}\right)$ was $30 \mathrm{~min}$ for all samples. As a consequence, there were differences in the amount of austenite $\left(f_{\gamma}^{i}\right)$ and its carbon content $\left(X_{C, \gamma}^{i}\right)$ at the end of the intercritical annealing between the three samples. The relevant parameters for the intercritical annealing step are collected in Table 2. After the intercritical annealing treatment, the samples were transferred immediately to a second salt bath kept at a temperature

Table 1

Chemical composition of the three TRIP steels used in this study (in wt.\%), with balance Fe.

\begin{tabular}{llllll}
\hline Material & $\mathrm{C}$ & $\mathrm{Mn}$ & $\mathrm{Si}$ & $\mathrm{Al}$ & $\mathrm{P}$ \\
\hline $\mathrm{Al}_{0.4}$ & 0.188 & 1.502 & 0.254 & 0.443 & 0.015 \\
$\mathrm{Al}_{1.8}$ & 0.218 & 1.539 & 0.267 & 1.750 & 0.018 \\
$\mathrm{Al}_{0.4} \mathrm{P}_{0.1}$ & 0.175 & 1.493 & 0.255 & 0.439 & 0.102 \\
\hline
\end{tabular}


Table 2

Relevant parameters during the intercritical annealing step for the three TRIP samples: the thermodynamic transformation temperatures $\left(A_{1}^{-}, A_{1}^{+}\right.$and $\left.A_{3}\right)$, the intercritical annealing temperature $\left(T_{\mathrm{i}}\right)$ and time $\left(t_{\mathrm{i}}\right)$, together with the austenite fraction $\left(f_{\gamma}^{i}\right)$ and its average carbon content $\left(X_{C, \gamma}^{i}\right)$ at the end of the intercritical annealing.

\begin{tabular}{lcclllll}
\hline Material & $A_{1}^{-}(\mathrm{K})$ & $A_{1}^{+}(\mathrm{K})$ & $A_{3}(\mathrm{~K})$ & $T_{\mathrm{i}}(\mathrm{K})$ & $t_{\mathrm{i}}(\min )$ & $f_{\gamma}^{i}(\%)$ & $X_{C, \gamma}^{i}(\mathrm{wt} . \%)$ \\
\hline $\mathrm{Al}_{0.4}$ & 967 & 983 & 1127 & 1073 & 30 & 37 & 0.508 \\
$\mathrm{Al}_{1.8}$ & 1016 & 1035 & - & 1173 & 30 & 52 & 0.419 \\
$\mathrm{Al}_{0.4} \mathrm{P}_{0.1}$ & 969 & 984 & 1147 & 1028 & 30 & 63 \\
\hline
\end{tabular}

Note: $\mathrm{Al}_{1.8}$ steel cannot be made in the pure austenite phase.

of $673 \mathrm{~K}$, where part of the intercritical austenite phase transformed into bainite. The bainitic holding time was fixed to $60 \mathrm{~s}$ for all samples, so that the influence of aluminium and phosphorus on the bainitic transformation kinetics could be assessed. After the bainitic holding treatment, the samples were quenched in water to room temperature.

The three resultant TRIP microstructures were characterized at room temperature by high-energy synchrotron $\mathrm{X}$-ray microdiffraction. The experiments were performed at the three-dimensional X-ray diffraction microscope (3DXRD) available at the ID11 beam line of the European Synchrotron Radiation Facility (Grenoble, France). An intense monochromatic X-ray beam with an energy of $80 \mathrm{keV}$ (wavelength of $0.155 \AA$ ) and a beam size of $28 \times 29 \mu \mathrm{m}^{2}$ illuminated the cylindrical sample. The diffracted intensity was recorded on a two-dimensional detector placed behind the sample. During an exposure time of $2 \mathrm{~s}$, the sample was continuously rotated around its cylindrical axis over an angle of $\Delta \omega=0.5^{\circ}$. In a series of exposures, the initial $\omega$-position was varied from -30 to $+30^{\circ}$. Grains that fulfilled the Bragg condition generated a diffraction spot on the two-dimensional detector. Due to the micrometer dimensions of the X-ray beam cross section and the limited angular rotation for each exposure, separate diffraction spots arising from individual grains appear within the austenite and ferrite diffraction rings. Additional scans were performed with a larger beam size of $39 \times 39 \mu \mathrm{m}^{2}$, to test whether the grains were completely illuminated by the X-ray beam.

The influence of aluminium and phosphorus on the stability of the metastable austenite grains present at room temperature was studied by cooling the TRIP samples from room temperature to $100 \mathrm{~K}$ in steps of $20 \mathrm{~K}$ using a nitrogen gas cryostream cooler (Oxford Cryosystems). In this way, we thermally induced the martensitic transformation of the metastable austenite grains by increasing the chemical driving force for the transformation [18]. In the present study, we chose to induce the martensitic transformation by a cooling process instead of an external stress due to its improved experimental accuracy. After each temperature step, the same illuminated sample volume was located by performing scans of the horizontal sample position, the vertical sample position and the sample rotation angle. For this purpose, the intensity of a selected diffraction spot from a characteristic non-transforming ferrite grain was used. After this sample repositioning, the diffraction pat- tern was recorded for each exposure during the $\omega$-scan for the two mentioned beam sizes. After reaching the lowest temperature of $100 \mathrm{~K}$, the samples were heated back to room temperature, at which diffraction patterns for the two beam sizes were also recorded for a direct comparison of the room-temperature microstructures before and after cooling.

\section{Results and discussion}

\subsection{Austenite grain volume and carbon content determination}

Fig. 1 shows a characteristic diffraction pattern of TRIP steel at room temperature. In this study we used the $\{200\}$, $\{220\}$ and $\{311\}$ austenite reflections and the $\{200\}$, $\{211\}$ and $\{220\}$ ferrite reflections to derive the austenite and ferrite phase fractions [29]. For this purpose, the total intensity corresponding to each reflection was obtained by adding all diffraction patterns measured during the $\omega$-scan from -30 to $+30^{\circ}$. The austenite reflections were further analysed to yield information about the characteristics and stability of the individual metastable austenite grains. Each austenite diffraction ring is composed of a number of spots originating from individual austenite grains in the TRIP sample, and a powder signal stemming from austenite grains whose volume falls below the experimental detection limit for individual grains. This detection limit is estimated to be about $5 \mu \mathrm{m}^{3}$ [30]. Each diffraction spot contains information about the characteristics of an individual austenite grain in the sample. The integrated intensity of the diffraction spot, properly corrected for the background ring [30], is directly proportional to the volume $\left(V_{\gamma}\right)$ of the grain from which it originates [31]. Furthermore, a peak fit analysis allowed us to determine the lattice parameter $\left(a_{\gamma}\right)$ of the austenite grain. The lattice parameter is in turn related to the grain's chemical composition via the following relationship [29,32]:

$a_{\gamma}=3.556+0.0453 x_{\mathrm{C}}+0.00095 x_{\mathrm{Mn}}+0.0056 x_{\mathrm{Al}}$

where $a_{\gamma}$ is in $\AA$ and $x_{\mathrm{C}}, x_{\mathrm{Mn}}$ and $x_{\mathrm{Al}}$ are in wt.\%. The presence of silicon does not influence the austenite lattice parameter within the experimental accuracy [33]. The influence of phosphorus on the austenite lattice parameter has not been reported, and is therefore assumed to be negligible for a content of $0.1 \mathrm{wt} . \% \mathrm{P}$. In our experiments, the 

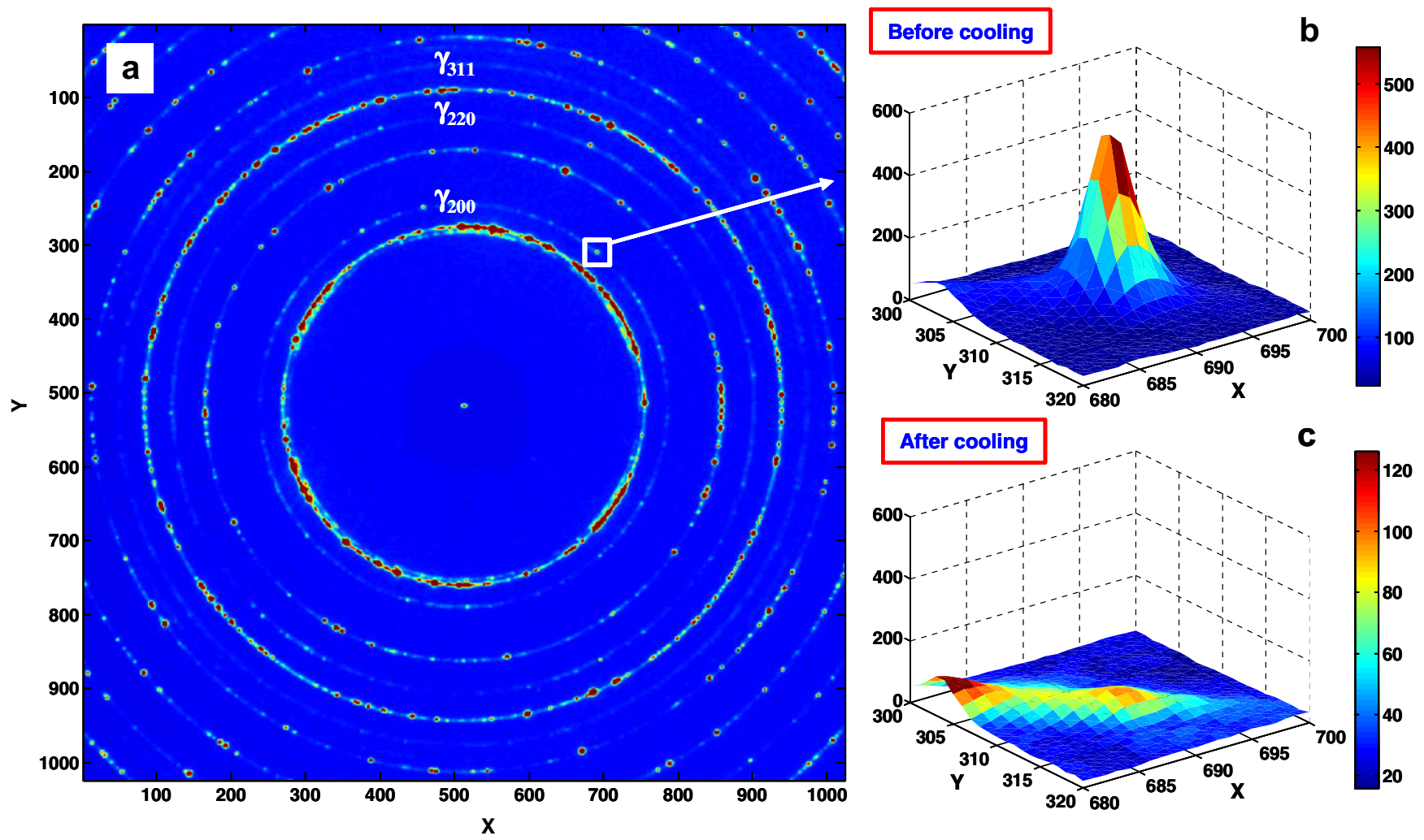

Fig. 1. X-ray diffraction pattern of $\mathrm{Al}_{1.8}$ steel, recorded by using a beam size of $28 \times 29 \mu \mathrm{m}^{2}$. (a) Complete two-dimensional diffraction pattern at room temperature. The $\{200\},\{220\}$ and $\{311\}$ austenite diffraction rings are denoted as $\gamma_{200}, \gamma_{220}$ and $\gamma_{311}$, respectively. (b) A single austenite diffraction peak from the $\{200\}$ ring at room temperature before cooling. (c) The same region as in (b) after cooling the sample to $100 \mathrm{~K}$ and heating it back to room temperature (taken from Ref. [26]).

systematic uncertainty in the determination of the carbon content from the austenite lattice parameter corresponds to $0.02 \mathrm{wt} . \%$.

\subsection{High-temperature processing of TRIP steels}

The TRIP samples were annealed in the $\gamma / \alpha$ stability region for $30 \mathrm{~min}$. Due to their differences in chemical composition and intercritical annealing temperature, different austenite fractions and austenite carbon contents were obtained for the studied materials at the end of this first step (see Section 2). The subsequent quenching was assumed to be fast enough to avoid the formation of further intercritical ferrite. The absence of $\mathrm{Fe}_{3} \mathrm{C}$ reflections in the room-temperature X-ray diffraction patterns confirmed that no significant amount of cementite was formed during the quenching process to a temperature of $673 \mathrm{~K}$. Therefore, the volume fraction and carbon content of austenite at the start of the bainitic transformation were considered to be equal to the values of the intercritical austenite (Table 2). The influence of aluminium and phosphorus on the bainitic transformation manifested itself in the degree of transformation and the increase in carbon content with respect to those intercritical values. During the isothermal step at $673 \mathrm{~K}$, part of the intercritical austenite transforms into carbide-free bainite. As a conse- quence of this process, two types of austenite grains with different size and morphology are present in the resultant TRIP microstructure at room temperature $[3,26,34]$ : very fine "film-type" austenite grains located between the bainitic plates, and larger "blocky-type" austenite grains which constitute the remaining parts of the intercritical austenite grains after partial bainitic transformation. Only the latter type of austenite grains has a volume larger than the experimental detection limit for individual grains of $5 \mu \mathrm{m}^{3}$. After a bainitic holding time of $60 \mathrm{~s}$, the samples were finally quenched to room temperature.

Fig. 2 displays the histograms of the number of retained austenite grains $\left(V_{\gamma}>5 \mu \mathrm{m}^{3}\right)$ as a function of carbon content and grain volume at room temperature. The number of grains and the average grain volume and carbon content values are collected in Table 3 . The presence of aluminium and phosphorus is known to accelerate the formation of bainite $[6,10,11,35]$. An increasing amount of both alloying elements would then result in a smaller grain size and a higher carbon content of the remaining austenite grains. However, the number of austenite grains present at room temperature turned out to be similar for the $\mathrm{Al}_{0.4}$ and $\mathrm{Al}_{1.8}$ samples (Table 3). Surprisingly, the grain volume distribution of the $\mathrm{Al}_{0.4}$ sample is significantly sharper and is shifted to lower grain volumes with respect to the $\mathrm{Al}_{1.8}$ sample. Moreover, the $\mathrm{Al}_{0.4}$ sample displays the smallest 

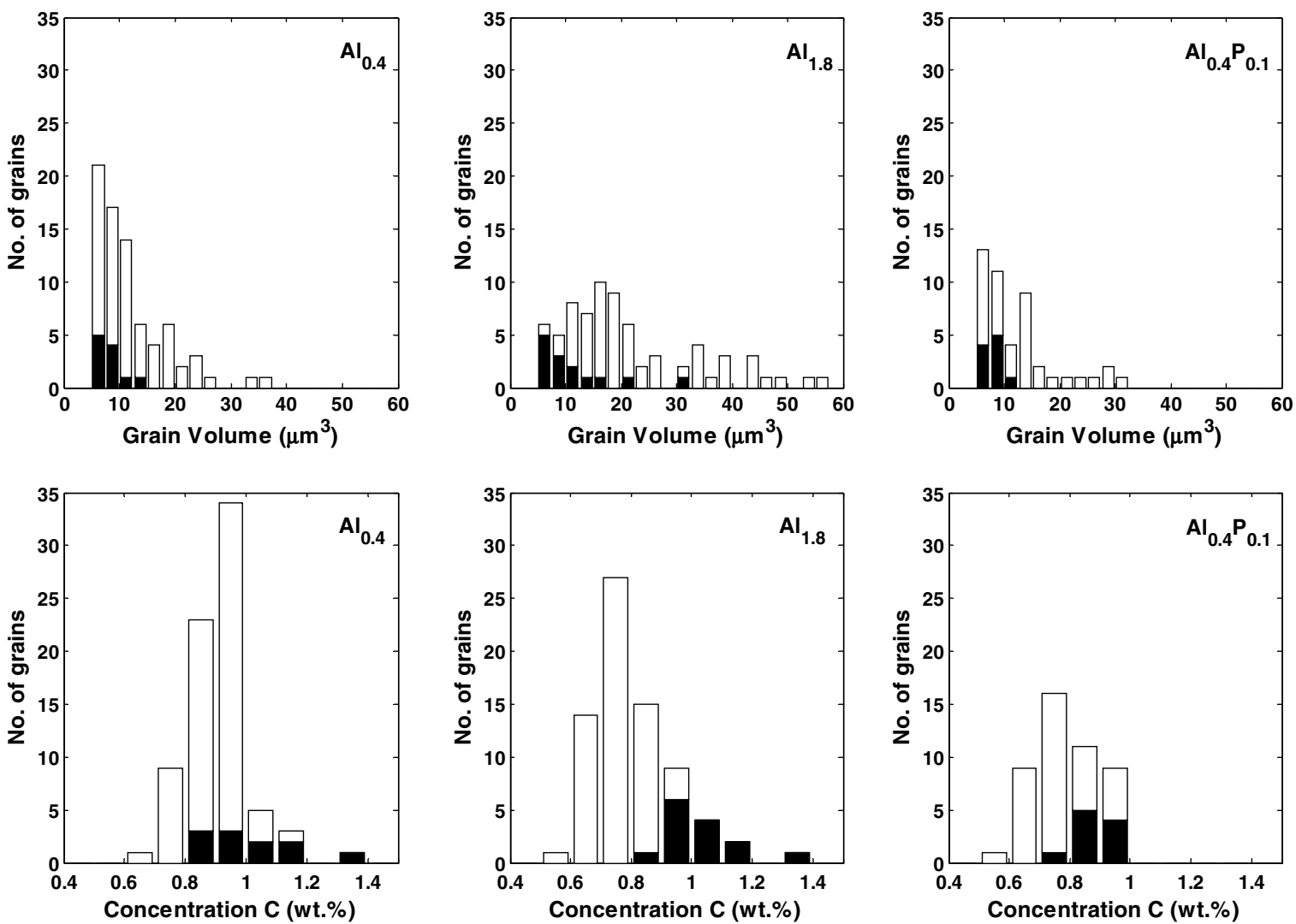

Fig. 2. Number of austenite grains above the detection limit for individual grains of $5 \mu \mathrm{m}^{3}$ at room temperature, as a function of the grain volume and carbon concentration for different aluminium and phosphorus contents $\left(\mathrm{Al}_{0.4}, \mathrm{Al}_{1.8}, \mathrm{Al}_{0.4} \mathrm{P}_{0.1}\right)$. The white bars correspond to the grain distribution before cooling, while the black bars represent the grain distribution after having cooled the TRIP sample down to $100 \mathrm{~K}$ and heated it back to room temperature.

Table 3

Total number of grains $\left(N_{\gamma}\right)$, average grain volume $\left(\left\langle V_{\gamma}\right\rangle\right)$ and carbon concentration $\left(<X_{\mathrm{C}}>\right)$ of the austenite grain distribution at room temperature (before and after cooling to $100 \mathrm{~K}$ ) as a function of the aluminium and phosphorus content.

\begin{tabular}{|c|c|c|c|c|c|c|}
\hline \multirow[t]{2}{*}{ Material } & \multicolumn{2}{|l|}{$N_{\gamma}$} & \multicolumn{2}{|l|}{$<V_{\gamma}>\left(\mu \mathrm{m}^{3}\right)$} & \multicolumn{2}{|c|}{$<X_{\mathrm{C}}>(\mathrm{wt} . \%)$} \\
\hline & Before & $\overline{\text { After }}$ & Before & After & Before & After \\
\hline & 76 & 11 & & & 0.92 & 1.0 \\
\hline 1.8 & 73 & 14 & $20.9(12.2)$ & $11.5(7.2)$ & 0.8 & 1.0 \\
\hline $\mathrm{l}_{0.4} \mathrm{P}_{0.1}$ & 46 & 10 & $12.3(6.6)$ & $8.0(2.1)$ & $0.80(0.11)$ & $0.89(0.08)$ \\
\hline
\end{tabular}

The width of the distribution (standard deviation) is indicated in parenthesis.

average grain size and the highest average carbon content of the three TRIP samples used in this study. This strong discrepancy can be explained by assuming that part of the austenite grains in the $\mathrm{Al}_{0.4}$ sample are not stable enough after the isothermal bainitic transformation step and already transformed into martensite during quenching from $673 \mathrm{~K}$ to room temperature. On the other hand, the $\mathrm{Al}_{0.4} \mathrm{P}_{0.1}$ sample presents the lowest number of austenite grains at room temperature, together with the largest carbon enrichment with respect to the carbon content of the intercritical austenite. Its average grain volume is significantly smaller than the case of the $\mathrm{Al}_{1.8}$ sample, and is just somewhat higher than the value of the $\mathrm{Al}_{0.4}$ sample. These results indicate that the addition of $0.1 \mathrm{wt} . \%$ of phosphorus exerts a stronger influence on the bainitic transformation behaviour than increasing the aluminium content to $1.8 \mathrm{wt} . \%$.

In order to evaluate the effect of the alloying elements on the chemical driving force for the formation of bainitic ferrite (and also for the martensitic transformation, as discussed in the next section), we have calculated the Gibbs free energy of austenite and ferrite in the whole temperature range up to $1300 \mathrm{~K}$, as a function of carbon content for the three TRIP compositions used. The values of the Gibbs free energy for the two phases above $300 \mathrm{~K}$ were derived from thermodynamic calculations using the MTDATA database. Below $300 \mathrm{~K}$, the Gibbs free energy estimation is based on the specific heat of each of the phases, assuming that no significant redistribution of chemical elements is taking place between both phases at those temperatures. The values are initially calculated for austenite and ferrite in pure iron (see Appendix A), and their difference $\left(\Delta G_{\gamma \rightarrow \alpha}=G_{\alpha}-G_{\gamma}\right)$ is then shifted for each of the studied compositions to normalize it to the value of the chemical driving force at $300 \mathrm{~K}$ obtained from the MTDATA calculations. The results for the $\mathrm{Al}_{0.4}$ steel are displayed in Fig. 3. These thermodynamic calculations indicate that the carbon exerts a stronger influence on $\Delta G_{\gamma \rightarrow \alpha}$ than the other alloying elements present in the 


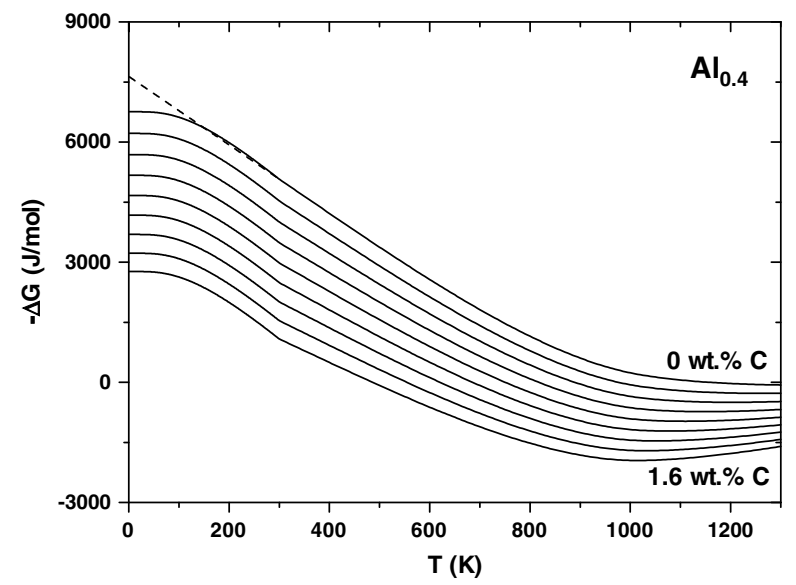

Fig. 3. Temperature dependence of the chemical driving force for the austenite $(\gamma)$ to ferrite $(\alpha)$ transformation $\left(-\Delta G_{\gamma \rightarrow \alpha}=G_{\gamma}-G_{\alpha}\right)$ for increasing carbon contents from 0 to $1.6 \mathrm{wt} . \%$, in steps of $0.2 \mathrm{wt} . \%$, for the chemical composition of the $\mathrm{Al}_{0.4}$ steel. The dashed line represents the low temperature linear approximation based on the value for the slope obtained at $300 \mathrm{~K}$ from MTDATA calculations.

studied TRIP samples. The variation of the $\Delta G_{\gamma \rightarrow \alpha}$ with the carbon content $\left(X_{\mathrm{C}}\right)$ is linear up to $1.6 \mathrm{wt} . \%$, with $\frac{d \Delta G_{\eta \rightarrow \alpha}}{d X_{C}}=$ $1820 \mathrm{~J} \mathrm{~mol}^{-1}$ wt. $\%^{-1}$ at $673 \mathrm{~K}$. Both aluminium and phosphorus act as ferrite stabilizers, and so increase the driving force for the transformation of austenite into bainitic ferrite. The value of $\Delta G_{\gamma \rightarrow \alpha}$ corresponding to the $\mathrm{Al}_{0.4}$ sample (with 0 wt.\% C) at $673 \mathrm{~K}$ is $-1996 \mathrm{~J} \mathrm{~mol}^{-1}$. The $\mathrm{Al}_{1.8}$ sample manifests a decrease of $35 \mathrm{~J} \mathrm{~mol}^{-1}$ in $\Delta G_{\gamma \rightarrow \alpha}$ with respect to the $\mathrm{Al}_{0.4}$ sample, while the addition of $0.1 \mathrm{wt} . \% \mathrm{P}$ leads to a decrease of only $0.5 \mathrm{~J} \mathrm{~mol}^{-1}$. These results indicate a stronger effect of aluminium on the stability of bainitic ferrite as compared to phosphorus.

Even though aluminium has a stronger influence on the chemical driving force for the formation of bainitic ferrite, our results indicate that the presence of phosphorus does lead to a larger degree of bainitic transformation, together with a higher carbon enrichment and a smaller volume of the remaining austenite grains. This points to an additional effect of the alloying elements on the kinetics of the bainitic transformation. Three-dimensional atom probe measurements have excluded the occurrence of partitioning of substitutional elements between the newly formed ferritic plates and the remaining austenite during the incomplete bainite transformation [35]. Moreover, there were no experimental indications of segregation of these elements to the vicinity of the transformation interface during the growth of the ferritic plates [36]. The formation of bainitic ferrite manifests itself as an increase in the powder signal within the ferrite rings, instead of producing additional separate Bragg reflections. This indicates that the bainitic ferrite plates have a low carbon content close to the one in the intercritically formed ferrite grains. Therefore, the carbon effectively diffuses out of the bainitic ferrite plates during the transformation. Due to the absence of cementite formation, the remaining austenite grains become significantly enriched in carbon with respect to the carbon con- tent after the intercritical annealing (see Table 3). Even though the substitutional elements do not significantly partition during the bainitic transformation, they influence the activity of carbon in the bainitic ferrite plates [37,38]. Aluminium is known to decrease the carbon activity in ferrite, and concomitantly the carbon solubility increases. This effect is not clearly seen in our results even for the $\mathrm{Al}_{1.8}$ sample, where the carbon content of the bainitic ferrite plates lies close to the equilibrium value. This may be due to the presence of silicon, which will effectively counteract the influence of aluminium on the carbon activity in ferrite [36,37]. The strong effect of phosphorus on the bainitic transformation observed in this study can be attributed to the significant increase that the phosphorus produces in the carbon activity in the bainitic ferrite plates. In the presence of phosphorus, the carbon atoms will diffuse more effectively out of the bainitic ferrite plates and into the surrounding austenite. As a consequence, the bainitic transformation is accelerated and higher carbon enrichment levels are obtained in the remaining austenite in the presence of phosphorus. These results also indicate that the carbon diffusion is the rate-limiting step in the bainitic transformation kinetics in the studied TRIP samples.

\subsection{Martensitic transformation of metastable austenite below room temperature}

We now consider the change in retained austenite characteristics for the three TRIP samples due to cooling to $100 \mathrm{~K}$. We monitored in situ the martensitic transformation of individual "blocky-type" metastable austenite grains larger than $5 \mu \mathrm{m}^{3}$ by following their volume as a function of temperature. Fig. 4 displays examples of the three transformation behaviours observed in the studied TRIP samples, while the volume fraction of the austenite grains larger than $5 \mu \mathrm{m}^{3}$ that remain untransformed after the cooling process is shown in Table 4. Most of the austenite grains transform completely into martensite in one temperature step (Fig. 4a). However, the temperature at which they transform into martensite (i.e. the martensitic transformation temperature, $M_{\mathrm{S}}$ ) varies strongly from grain to grain. A second transformation behaviour corresponds to a small fraction of the austenite grains that show an incomplete transformation into martensite (Fig. 4b). In some of these cases, a subsequent transformation is observed at lower temperatures. This behaviour most likely corresponds to two spatially separated austenite grains that originally formed part of a bigger intercritical austenite grain. However, differences in stability within individual austenite grains due to carbon gradients cannot be completely discarded as an explanation for this observation [39]. Finally, a number of grains remain untransformed down to $100 \mathrm{~K}$ (Fig. 4c). The variation of $\Delta G_{\gamma \rightarrow \alpha}$ approaches a constant value below $100 \mathrm{~K}$ (Fig. 3). This indicates that cooling below $100 \mathrm{~K}$ is not expected to create a significant amount of new unstable austenite grains. The observed differences in transformation behaviour with the 

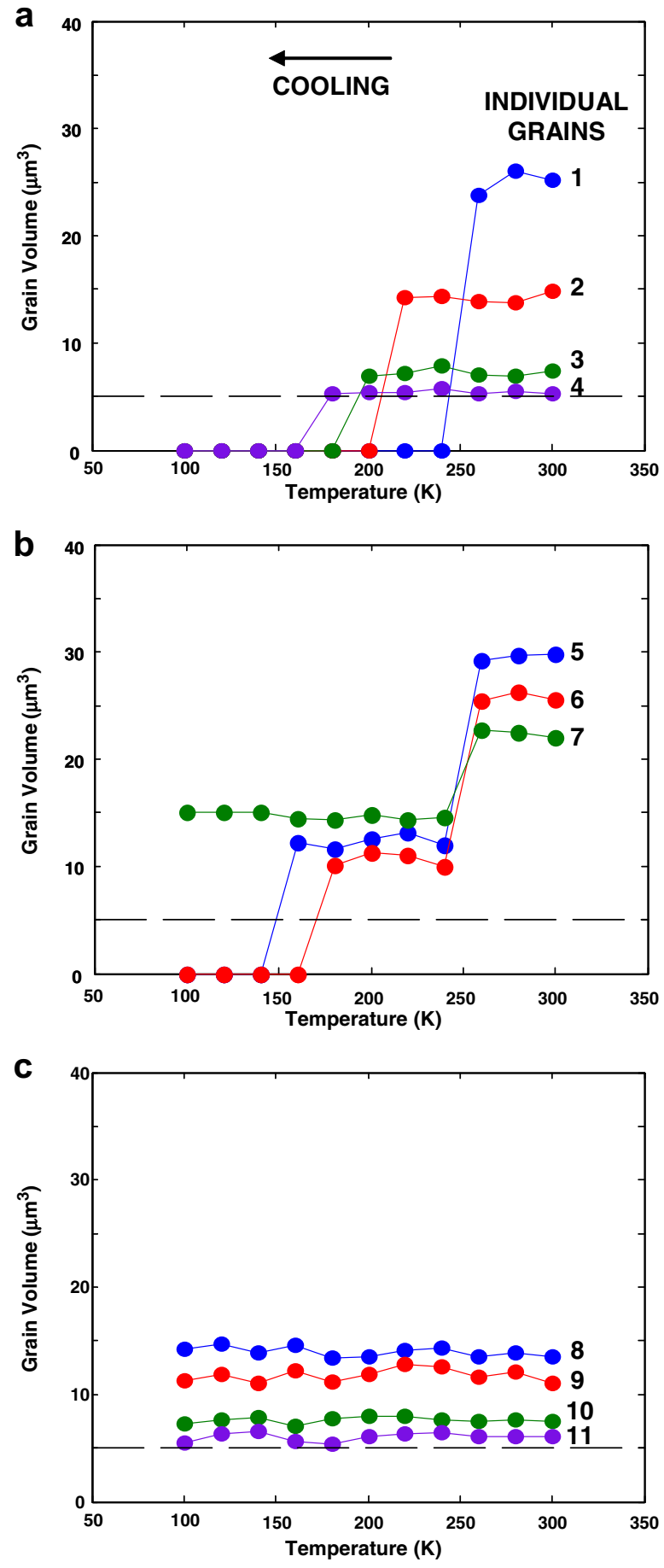

Fig. 4. Observed transformation behaviours of the individual austenite grains: (a) grains that transform completely into martensite in a single temperature step (1-4); (b) grains that partly transform into martensite (57). For some of these grains, a second transformation is observed at a lower temperature $(5,6)$; (c) grains that remain untransformed down to $100 \mathrm{~K}(8-11)$. The dash lines indicate the experimental detection limit for individual grains.

austenite phase reinforce the necessity to understand and control the austenite stability at the level of individual grains to achieve improved combinations of mechanical properties.
Table 4

Total volume fraction of the austenite phase at room temperature as a function of the chemical composition, before and after cooling the TRIP material to $100 \mathrm{~K}$ (taken from Ref. [29]). The volume fraction corresponding to the austenite grains whose volume is either above or below the experimental detection limit for individual grains of $5 \mu \mathrm{m}^{3}$ is also shown.

\begin{tabular}{llll}
\hline & $\mathrm{Al}_{0.4}$ & $\mathrm{Al}_{1.8}$ & $\mathrm{Al}_{0.4} \mathrm{P}_{0.1}$ \\
\hline$f_{\gamma, \text { tofore }}^{\text {total }}(\%)$ & $7.49(5)$ & $7.71(6)$ & $5.83(5)$ \\
$f_{\gamma, \text { after }}^{\text {total }}(\%)$ & $4.97(4)$ & $5.03(5)$ & $3.63(4)$ \\
$f_{\gamma, \text { after }}^{\text {total }} / f_{\gamma, \text { before }}^{\text {total }}(\%)$ & 66 & 65 & 62 \\
$f_{\gamma, \text { after }}^{>5} / f_{\gamma, \text { before }}^{>5}(\%)$ & 10 & 11 & 14 \\
$f_{\gamma, \text { after }}^{>5 \mathrm{~m}^{3}} / f_{\gamma, \text { before }}^{>5}(\%)$ & 77 & 100 & 64 \\
\hline
\end{tabular}

The influence of the local microstructural characteristics on the austenite stability has been assessed by linking the grain size $\left(V_{\gamma}\right)$ and local carbon content $\left(x_{\mathrm{C}}\right)$ of each of the studied individual austenite grains to the observed martensitic transformation temperature $\left(M_{\mathrm{S}}\right)$. In Fig. 5 the austenite grains are classified according to their stability, while the grain volume and carbon content distributions of the non-transforming grains are shown in Fig. 2 together with the characteristics of the retained austenite grains before cooling to $100 \mathrm{~K}$. The grain volume and carbon content distributions have become narrower as a consequence of the transformation of part of the austenite grains into martensite during cooling. The distributions have also shifted to lower values of grain volume and higher carbon contents. The $M_{\mathrm{S}}$ temperature depends on the grain size and local carbon content according to [26,27]:

$M_{\mathrm{S}}=M_{\mathrm{S} 0}-A x_{\mathrm{C}}-B V_{\gamma}^{-\frac{1}{3}}$

where the first two terms of this expression reflect the wellknown Andrews' empirical relationship between $M_{\mathrm{S}}$ and the carbon content, with $A=425 \mathrm{~K} \mathrm{wt} . \%^{-1}$ [40], while the third term manifests the effect of the grain volume on its stability. This expression has been derived assuming that the chemical driving force for the transformation depends linearly on temperature and carbon content [26]. Our thermodynamic calculations confirm the linear dependence of $\Delta G_{\gamma \rightarrow \alpha}$ with the carbon content for the three studied samples. The difference between the exact variation of $\Delta G_{\gamma \rightarrow \alpha}$ with temperature and the linear approximation is only significant when approaching the lowest measured temperature of $100 \mathrm{~K}$ (see Fig. 3).

The best estimates for the boundaries between different stability regions have been obtained using the values of $M_{\mathrm{S} 0}=702 \mathrm{~K}$ and $B=475 \mu \mathrm{m} \mathrm{K}$ (Fig. 5). The observed overlap between stability regions can be attributed to the role that other microstructural parameters, such as the geometrical grain shape, the dislocation density and the nature of the surrounding grains, may play in the stability of the austenite grains. The effect of the grain volume on the austenite stability can be best appreciated in Fig. 6 . The $M_{\mathrm{S}}$ temperature decreases significantly with the grain volume below $20 \mu \mathrm{m}^{3}$ for the three samples. Therefore, the stability 

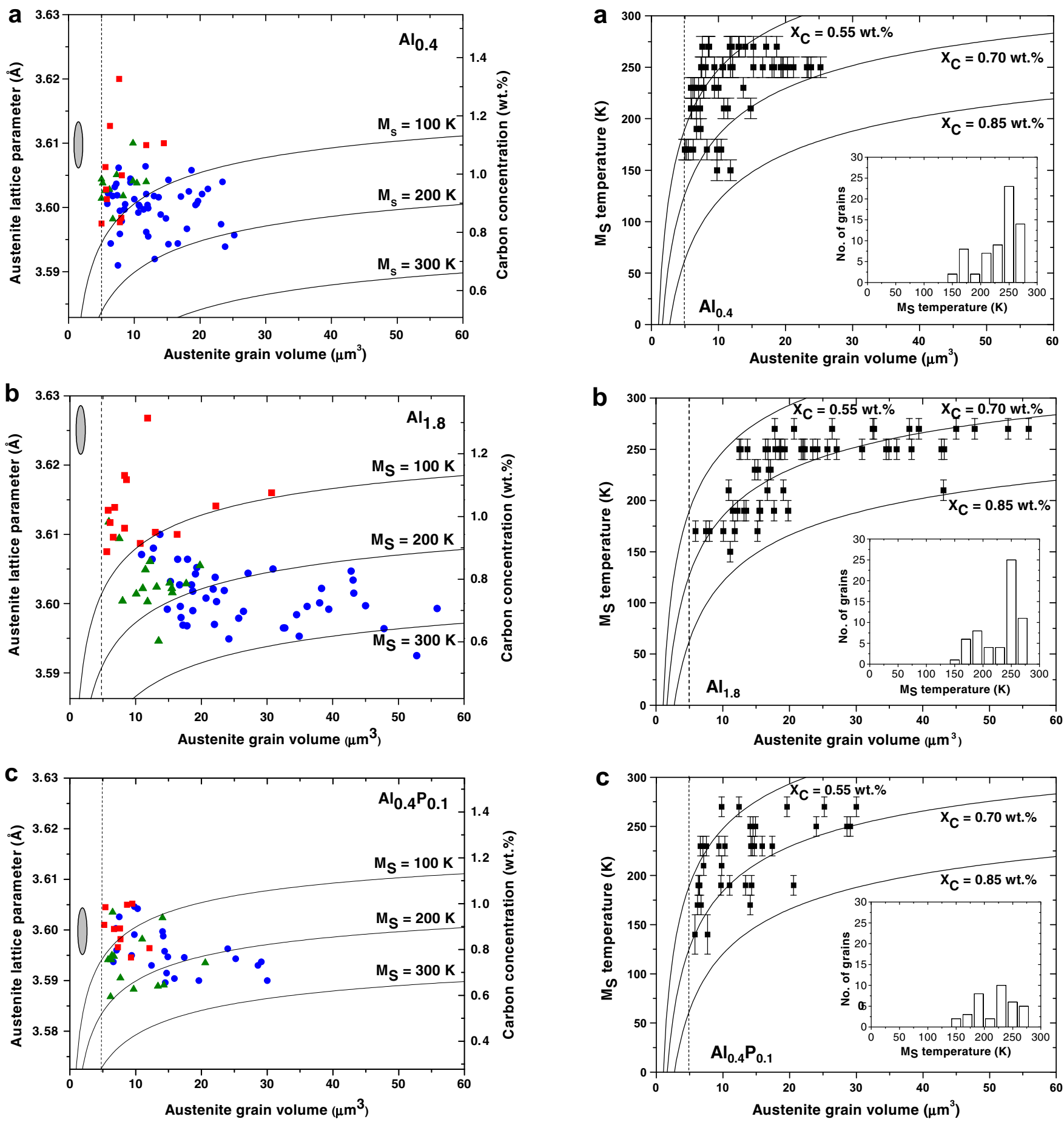

Fig. 5. Lattice parameter and corresponding carbon content of the individual austenite grains as a function of their grain volume for the three TRIP samples: (a) $\mathrm{Al}_{0.4}$, (b) $\mathrm{Al}_{1.8}$ and (c) $\mathrm{Al}_{0.4} \mathrm{P}_{0.1}$. The blue circles represent austenite grains that transform in the temperature range of $200<T<300 \mathrm{~K}$, while the green triangles indicate austenite grains that transform in the temperature range of $200<T<100 \mathrm{~K}$. The red squares correspond to the austenite grains that remain stable during cooling to $100 \mathrm{~K}$. The grey area represents the austenite grains whose volume falls below the detection limit for individual grains of $5 \mu \mathrm{m}^{3}$ (dashed line). The solid lines are the estimates of Eq. (2) for three constant martensitic transformation temperatures $\left(M_{\mathrm{S}}\right)$. The marker size corresponds to the experimental error. (For interpretation of the references to colour in this figure legend, the reader is referred to the web version of this article.)

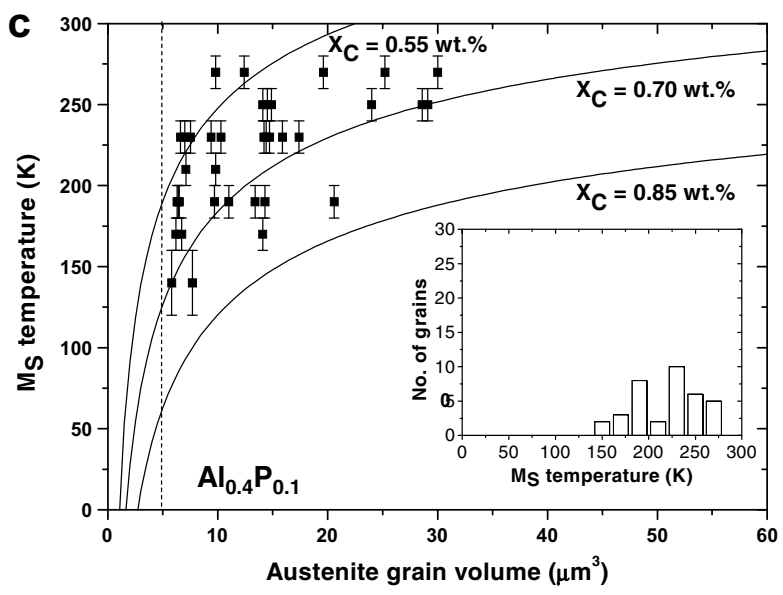

Fig. 6. Martensitic transformation temperature of the individual austenite grains as a function of their grain volume for the three TRIP samples: (a) $\mathrm{Al}_{0.4}$, (b) $\mathrm{Al}_{1.8}$ and (c) $\mathrm{Al}_{0.4} \mathrm{P}_{0.1}$. The solid lines represent the estimates of Eq. (2) for three constant carbon contents $\left(X_{\mathrm{C}}\right)$. The dash lines indicate the experimental detection limit for individual grains. The number of grains as a function of the martensitic transformation temperature is shown as an inset for each of the three TRIP samples.

of austenite grains with a larger volume is mainly controlled by their local carbon content, while both parameters play a role below $20 \mu \mathrm{m}^{3}$.

Table 3 collects the number of austenite grains, the average grain volume and the average carbon content for the 
three samples before and after the cooling process. The histograms of the number of transforming grains as a function of the $M_{\mathrm{S}}$ temperature are displayed as insets in Fig. 6. The $\mathrm{Al}_{0.4}$ and $\mathrm{Al}_{1.8}$ samples undergo a similar degree of transformation, reaching an equivalent value for the final austenite carbon content. The average austenite grain size after cooling to $100 \mathrm{~K}$ is larger for the $\mathrm{Al}_{1.8}$ sample than for the $\mathrm{Al}_{0.4}$ sample. The average $M_{\mathrm{S}}$ temperature takes a value of $233 \mathrm{~K}$ for $\mathrm{Al}_{0.4}$ and $232 \mathrm{~K}$ for $\mathrm{Al}_{1.8}$, respectively. However, the thermodynamic calculations indicate that the driving force for the martensitic transformation increases with the aluminium content, leading to a lower stability of the austenite grains. Bearing this in mind and considering the larger grain volume and lower carbon content of austenite in the $\mathrm{Al}_{1.8}$ sample before cooling, this sample would present a higher degree of transformation into martensite than the $\mathrm{Al}_{0.4}$ sample. Therefore, the aluminium must exert an additional stabilizing effect on the metastable austenite grains. The aluminium atoms are known to cause an increase in the stacking fault energy in austenite of $5-10 \mathrm{~mJ} \mathrm{~m}^{-2}$ per $1 \mathrm{wt} . \% \mathrm{Al}$, according to relatively recent thermodynamic calculations [41,42]. The martensite plates are considered to nucleate at shear bands that result from the overlap of stacking faults. The faults in the stacking of close-packed planes are in turn generated by the movement of Shockley partial dislocations that result from the dissociation of groups of dislocations [43]. Therefore, the increase in the stacking fault energy due to the presence of aluminium atoms results in a lower density of potential sites for the nucleation of martensite. This leads to a decrease in the value of $M_{\mathrm{S} 0}$ in Eq. (2). Therefore, the tendency of the austenite grains to transform into martensite is reduced due to the increase in aluminium content.

With respect to the effect of phosphorus on the austenite stability, our results reveal a lower fraction of austenite grains transformed into martensite for the $\mathrm{Al}_{0.4} \mathrm{P}_{0.1}$ sample when compared to the $\mathrm{Al}_{0.4}$ sample. Moreover, the $\mathrm{Al}_{0.4} \mathrm{P}_{0.1}$ sample undergoes a substantially lower carbon enrichment of the austenite phase during cooling to $100 \mathrm{~K}$, and this sample also presents a lower average value of the $M_{\mathrm{S}}$ temperature $(219 \mathrm{~K})$. The presence of phosphorus atoms increases the chemical driving force for the transformation. Furthermore, experimental data reveal a decrease in the stacking fault energy of approx. $25 \mathrm{~mJ} \mathrm{~m}^{-2}$ per $0.1 \mathrm{wt} . \% \mathrm{P}$ [44]. So the effect of phosphorus on both the chemical driving force for the transformation and the stacking fault energy would promote a larger degree of martensitic transformation than the one experimentally observed in the $\mathrm{Al}_{0.4} \mathrm{P}_{0.1}$ sample. However, phosphorus is reported to produce a strong solid solution strengthening effect in ferrite $[6,11]$. This effect is not significantly produced by aluminium [11], and leads to an enhanced matrix constraint that opposes the lattice expansion associated to the martensitic transformation of the whole metastable austenite grain. Consequently, the $M_{\mathrm{S} 0}$ value in Eq. (2) reduces with the addition of phosphorus.
This effect seems to counterbalance the favourable contribution of the phosphorus atoms to the chemical driving force and to the stacking fault energy, so that part of the austenite phase with a relatively low carbon content remains untransformed during the cooling to $100 \mathrm{~K}$. This observation is also in line with micromechanical predictions on the effect of strengthened surrounding ferritic grains on the stability of the metastable austenite grains $[24,25]$.

Finally, information about the small austenite grains $\left(V_{\gamma}<5 \mu \mathrm{m}^{3}\right)$ was obtained by performing a powder analysis of the background signal present within the austenite diffraction rings. This background signal originates from the "film-type" austenite grains located between the bainitic plates and from a fraction of the "blocky-type" grains that presents a volume below $5 \mu \mathrm{m}^{3}$. Table 4 shows the volume fraction of the austenite grains smaller than $5 \mu \mathrm{m}^{3}$ that remain untransformed after the cooling process. The average carbon content of these grains before cooling, derived from the average diffraction angle of the background signal, is represented as a grey area in Fig. 5. The results indicate that none of these small grains transform into martensite in the case of the $\mathrm{Al}_{1.8}$ sample, while a significant part of them is not stable enough to withstand the cooling to $100 \mathrm{~K}$ in the $\mathrm{Al}_{0.4}$ and $\mathrm{Al}_{0.4} \mathrm{P}_{0.1}$ samples. Recent tensile experiments on TRIP steels indicated that the "film-type" austenite grains do not transform into martensite until the onset of necking [34,45]. Therefore, the observed transformation behaviour can be ascribed to the small "blocky-type" grains. The high stability of these grains in the $\mathrm{Al}_{1.8}$ sample stems from a relatively large carbon content (1.25 wt.\%), coupled with the increase in stacking fault energy associated with the high aluminium content present in this sample. By contrast, more than $20 \%$ of the grains with lower carbon content in the $\mathrm{Al}_{0.4}$ sample transform into martensite and, consequently, the average carbon content increases from 1.10 to $1.18 \mathrm{wt} . \%$. This is also the case for the small grains present in the $\mathrm{Al}_{0.4} \mathrm{P}_{0.1}$ sample, where more than $30 \%$ of the small grains transform during cooling. The corresponding carbon content increases from 0.89 to 0.99 wt.\%. This relatively low final carbon content (as compared to the two phosphorus-free samples) can be attributed to the additional stabilization effect that the phosphorus causes on the austenite phase via a strong solid solution strengthening of the surrounding ferritic matrix.

\section{Conclusions}

We have assessed the effect of aluminium and phosphorus on the stability of individual metastable austenite grains in low-alloyed TRIP steels by performing in situ synchrotron X-ray diffraction experiments during cooling from room temperature to $100 \mathrm{~K}$. The main conclusions of the present study are: 
1. The stability of the larger austenite grains is mainly governed by their local carbon content. However, the grain volume plays an increasing role in the austenite stability below $20 \mu \mathrm{m}^{3}$. The observed stability distribution within the austenite phase stems from significant differences in grain volume and carbon content from grain to grain.

2. The microstructural characteristics of the retained austenite at room temperature depend on the aluminium and phosphorus content in the starting material. An increase in the aluminium content results in a higher stability of the austenite phase immediately after the bainitic holding time, so that it withstands the subsequent quenching to room temperature. This can be attributed to the increase in the chemical driving force for the formation of bainitic ferrite due to the presence of aluminium. However, phosphorus exerts a greater influence on the bainitic transformation kinetics than aluminium, due to its effect on the rate-limiting carbon diffusion out of the ferritic plates.

3. The addition of aluminium and phosphorus does not lead to a larger degree of martensitic transformation of the individual austenite grains $\left(V_{\gamma}>5 \mu \mathrm{m}^{3}\right)$ during cooling to $100 \mathrm{~K}$, despite the increase in the driving force for the transformation. Therefore, the presence of aluminium and phosphorus implies an additional stabilizing effect on the metastable austenite grains with respect to their transformation into martensite.

\section{Acknowledgements}

We acknowledge the European Synchrotron Radiation Facility for the provision of synchrotron radiation facilities and thank L. Margulies for assistance with the beam line ID11. We thank G. Song for the EDS characterization of the starting TRIP materials. This research was carried out under the Project No. MC5.07296 in the framework of the Research Program of the Materials innovation institute M2i (www.m2i.nl), the former Netherlands Institute for Metals Research.

\section{Appendix A. Gibbs free energy of austenite and ferrite in pure iron below $300 \mathrm{~K}$}

The Gibbs free energy $G$ at low temperatures is directly related to the entropy $S$ and the specific heat $C_{p}$ :

$C_{p}=T\left(\frac{\partial S}{\partial T}\right)_{p}=-T\left(\frac{\partial^{2} G}{\partial T^{2}}\right)_{p}$

where $T$ is the temperature and $p$ the pressure. For each of the two phases, three contributions to the specific heat must be considered: (1) the conduction electrons, (2) the lattice vibrations or phonons and (3) the magnetic phenomena.

1. The specific heat of the conduction electrons $\left(C_{e}\right)$ corresponds to:

$$
C_{e}(T)=\gamma T
$$

where $\gamma$ is the Sommerfeld coefficient. For ferrite this coefficient amounts to $\gamma=4.741 \mathrm{~mJ} \mathrm{~mol}^{-1} \mathrm{~K}^{-2}[46,47]$. Austenite and ferrite are expected to have comparable values for the Sommerfeld coefficient [48].

2. The phonon contribution to the specific heat is expressed by the following formula according to the Debye model:

$C_{p h}=9 R\left(\frac{T}{\theta_{D}}\right)^{3}\left(\int_{0}^{\theta_{D} / T} \frac{x^{4} e^{x}}{\left(e^{x}-1\right)^{2}} d x\right)$

where the Debye temperature $\left(\theta_{D}\right)$ takes the value of 430 and $335 \mathrm{~K}$ for ferrite and austenite, respectively [48].

3. Ferrite becomes ferromagnetically ordered below its Curie temperature of $T_{\mathrm{C}}=1043 \mathrm{~K}$. The corresponding spin wave contribution to the specific heat at temperatures lower than $300 \mathrm{~K}\left(T \ll T_{\mathrm{C}}\right)$ takes the form:

$C_{m}=\delta T^{3 / 2}$

with $\delta=0.021 \mathrm{~mJ} \mathrm{~mol}^{-1} \mathrm{~K}^{-5 / 2}[46,47]$. Austenite presents an antiferromagnetic ordering below its Néel temperature, the value of which varies within the range of 55 $80 \mathrm{~K}$, depending on the grain size $[49,50]$. Its paramagnetic behaviour can be described in terms of a two-level system with a continuous repopulation of spin states $[48,51]$. The corresponding magnetic term to the specific heat amounts to:

$C_{m}=R\left(\frac{\Delta}{T}\right)^{2} \frac{\exp \left(\frac{\Delta}{T}\right)}{\left(1+\exp \left(\frac{\Delta}{T}\right)\right)^{2}}$

with a level splitting of $\Delta=411 \mathrm{~K}$.

\section{References}

[1] Militzer M. Science 2002;298:975

[2] De Cooman BC. Curr Opin Solid State Mater Sci 2004;8:285.

[3] Timokhina IB, Hodgson PD, Pereloma EV. Metall Mater Trans A 2004;35A:2331.

[4] Zaefferer S, Ohlert J, Bleck W. Acta Mater 2004;52:2765.

[5] Jacques PJ. Curr Opin Solid State Mater Sci 2004;8:259.

[6] Chen CH, Era H, Shimizu M. Metall Trans A 1989;20A:437.

[7] Sakuma Y, Matlock DK, Krauss G. Metall Trans A 1992;23A:1221.

[8] Girault E, Mertens A, Jacques P, Houbert Y, Verlinden B, Van Humbeeck J. Scripta Mater 2001;44:885.

[9] Jacques PJ, Girault E, Mertens A, Verlinden B, van Humbeeck J, Delannay F. ISIJ Int 2001;41:1068.

[10] Mahieu J, Maki J, De Cooman BC, Claessens S. Metall Mater Trans A $2002 ; 33 \mathrm{~A}: 2573$.

[11] Traint S, Pichler A, Hauzenberger K, Stiaszny P, Werner E. Steel Res 2002;73:259.

[12] Mertens A, Jacques PJ, Zhao L, Kruijver SO, Sietsma J, Delannay F. J Phys IV 2003;112:305.

[13] Suh DW, Park SJ, Oh CS, Kim SJ. Scripta Mater 2007;57:1097.

[14] Heller T, Nuss A. Ironmaking Steelmaking 2005;32:303.

[15] Pereloma EV, Timokhina IB, Russell KF, Miller MK. Scripta Mater 2006;54:471.

[16] Shi W, Lin L, Yang CX, Fu RY, Wang L, Wollants P. Mater Sci Eng A 2006;429:247.

[17] Wang XD, Huang BX, Wang L, Rong YH. Metall Mater Trans A 2008;39A:1. 
[18] Berrahmoune MR, Berveiller S, Inal K, Moulin A, Patoor E. Mater Sci Eng A 2004;378:304.

[19] Tomota Y, Tokuda H, Adachi Y, Wakita M, Minakawa N, Moriai A, et al. Acta Mater 2004;52:5737.

[20] Sugimoto K, Kobayashi M, Nagasaka A, Hashimoto S. ISIJ Int 1995;35:1407.

[21] Sugimoto K, Nagasaka A, Kobayashi M, Hashimoto S. ISIJ Int 1999;39:56.

[22] Mintz B. Int Mater Rev 2001;46:169.

[23] Senuma T. ISIJ Int 2001;41:520.

[24] Tjahjanto DD, Turteltaub S, Suiker ASJ, Van der Zwaag S. Modell Simul Mater Sci Eng 2006;14:617.

[25] Tjahjanto DD, Suiker ASJ, Turteltaub S, Rivera Diaz del Castillo PEJ, van der Zwaag S. Comput Mater Sci 2007;41:107.

[26] Jimenez-Melero E, van Dijk NH, Zhao L, Sietsma J, Offerman SE, Wright JP, et al. Scripta Mater 2007;56:421.

[27] Jimenez-Melero E, van Dijk NH, Zhao L, Sietsma J, Offerman SE, Wright JP, et al. Acta Mater 2007;55:6713.

[28] Turteltaub S, Suiker ASJ. Int J Solids Struct 2006;43:7322.

[29] vanDijk NH, Butt AM, Zhao L, Sietsma J, Offerman SE, Wright JP, et al. Acta Mater 2005;53:5439.

[30] Jimenez-Melero E, van Dijk NH, Zhao L, Sietsma J, van der Zwaag S. Adv X-ray Anal 2007;51:69.

[31] Warren BE. X-ray diffraction. New York: Dover Publications; 1990.

[32] Scott CP, Drillet J. Scripta Mater 2007;56:489.

[33] Dyson DJ, Holmes B. J Iron Steel Inst 1970;208:469.

[34] Jacques PJ, Ladrière J, Delannay F. Metall Mater Trans A 2001;32A:2759.
[35] Pereloma EV, Timokhina IB, Miller MK, Hodgson PD. Acta Mater 2007;55:2587.

[36] Stark I, Smith GDW, Bhadeshia HKDH. Metall Mater Trans A 1990;21A:837.

[37] De Meyer M, Mahieu J, De Cooman BC. Mater Sci Technol 2002;18:1121.

[38] Leslie WC, Rauch GC. Metall Mater Trans A 1978; 9A:343.

[39] Stone HJ, Peet MJ, Bhadeshia HKDH, Withers PJ, Babu SS, Specht ED. Proc R Soc A 2008;464:1009.

[40] Andrews KW. J Iron Steel Inst 1965;203:721.

[41] Yang WS, Wan CM. J Mater Sci 1990;25:1821.

[42] Dumay A, Chateau JP, Allain S, Migot S, Bouaziz O. Mater Sci Eng A 2008;483-484:184.

[43] Olson GB, Cohen M. Metall Mater Trans A 1976;7A:1897.

[44] Gerasimov VI, Ryabchenkov AV, Butkevich VG, Aksenova LI, Chigal V, Kashova I, et al. Prot Metal 1977;13:555.

[45] Bai DQ, Di Chiro A, Yue S. Mater Sci Forum 1998;284-6:253.

[46] Dixon M, Hoare FE, Holden TM, Moody DE. Proc R Soc A 1965;285:561.

[47] Wohlfarth EP. Ferromagnetic materials, a handbook on the properties of magnetically ordered substances, vol. 1. Amsterdam: North Holland Publishing Company; 1980.

[48] Kaufman L, Clougherty EV, Weiss RJ. Acta Metall 1963;11:323.

[49] Tsunoda Y. J Phys Condens Matter 1989;1:10427.

[50] Bhadeshia HKDH. Ironmaking Steelmaking 2007;34:194.

[51] Bendick W, Pepperhoff W. Acta Metall 1982;30:679. 